\title{
Marketing Strategy, Vertical Structure, and Performance in the Lodging Industry A Contingency Approach
}

\author{
Chekitan S. Dev \\ School of Hotel Administration \\ Cornell University \\ Ithaca, NY 14853 \\ James R. Brown \\ R.B. Pamplin College of Business \\ Virginia Polytechnic Institute and State University \\ Blacksburg, VA 24061-0236
}

\begin{abstract}
The objective of this study was to examine, from a contingency perspective, marketing strategy, structure, and performance in the lodging industry. Specifically, the extent to which a hotel's business activities are vertically structured was posited to depend upon the fit between its strategy and the degree of dynamism in its task environment. In addition, a hotel's efficiency was believed to be affected by the match among its vertical structure, its strategy, and the volatility in its task environment. The empirical results indicated that a hotel's vertical structure was indeed significantly related to the interaction between its strategy and its task environment dynamism. The contingency approach, however, produced much less striking results in attempting to account for variation in a hotel's efficiency.
\end{abstract}




\section{Introduction}

The coalignment among a firm’s structure and strategy along with its environment determine the organization's level of performance and, hence, its survival (Thompson, 1967; Lenz, 1980). This coalignment results from two forces. On the one hand, the choice of strategy and structure may be determined by the control that the organization can achieve over the elements of its environment (e.g. suppliers, customers, etc.). On the other hand, the nature of environmental influences can dictate the most appropriate strategy and structure for the organization given its capabilities. Thus, the organization reacts to and affects its environment to realize effective levels of performance.

Walker and Ruekert (1987, p. 18) note, however, that:

Though the question of external environmental fit with business-level strategy is important, very little empirical evidence is available on which environmental variables are key and how business unit strategies and structures must coalign for successful implementation.

The goal of this study, therefore, is to add to this very small body of empirical knowledge. Specifically, this paper examines, from a contingency perspective, how the coalignment of an organization's task environment, its business strategy, and its vertical structure for organizing business activities impacts its performance.

The context of the empirical research reported here is the lodging industry. This industry represents a substantial segment of the economy, accounting for 1\% of the U.S. domestic GNP, employing 1.4 million persons, and generating \$50 billion in sales (Dev, 1988), In addition, firms within the industry are organized along a variety of vertical structures, pursue a number of different business strategies, and face widely varying task environments. In other words, the industry provides enough variation in the key constructs to allow for an empirical investigation of the contingency perspective of marketing strategy, structure, and performance.

The paper is organized as follows. First, the key concepts under study are discussed. Next, based on a review of the literature, preliminary hypotheses linking these constructs are developed. Third, an empirical study designed to test these hypotheses is then described. Finally, the implications of the results of this study, for both researchers and managers, are discussed. 


\section{The concepts under study}

\section{Vertical structure (i.e. operating arrangement)}

Vertical structure, in this research, pertains to the degree to which an individual hotel property's operations are controlled by others in the hospitality channel of distribution (Lewis and Chambers, 1989). For example, because corporate policy dictates how a company-owned and managed property (e.g. Fairlane Hyatt in Dearborn, Michigan) is to be managed and marketed, this property faces a high degree of vertical control. The activities of an independent property, on the other hand, are not controlled by others in the channel. Accordingly, independent properties are characterized by low degrees of vertical control. In between these two extremes fall centrally managed properties (e.g. AIRCOA), franchised properties (e.g. Holiday Inns), properties belonging to consortiums (e.g. Best Western), properties belonging to reservations networks (Steigenberger Reservation Service), and properties affiliated with other, independent properties (e.g. Quality Inns and Clarion Hotels) (see Lewis and Chambers, 1989, Chapter 18).

In this research, five different types of vertical structure are considered. The first general category is hotel chains. ${ }^{*}$ These are lodging organizations that operate a number of units under a common name and typically under common ownership. Three different chain structures in the lodging industry are possible. The chain owned and managed structure, as described above, is the most vertically controlled operating arrangement. Here the individual hotel property is owned by the corporation and operated by corporate employees. Chain leased and managed structures, with the next highest degree of vertical control, occur when the corporation leases the individual hotel from private investors and manages that property as if it were corporate-owned. Chain managed properties are simply managed, possibly under a different name, for independent investors. This operating arrangement represents the third highest level of vertical control.

The fourth type of vertical structure is the franchised operating arrangement. Franchised properties are operated as independent businesses under license from a national organization such as Ramada Inns, Hilton Hotels, or Holiday Corporation. They follow standardized operating and marketing plans, benefit from national advertising, and are interlinked via a computerized reservations network.

\footnotetext{
* The term 'chain' is often used to refer to both the franchise and corporate operating arrangements (i.e. vertical structures). In this study, we use 'chain' to refer solely to the corporate form of operation.
} 
Finally, independently owned and managed properties are not affiliated with any other lodging organization. As noted above, these structures represent the least amount of vertical control of the five operating arrangements examined here.

\section{Task environment}

Organizations do not operate in a vacuum. Their customers, competitors, and suppliers as well as governmental agencies regulating their activities impact their overall objectives, business strategies, and organization structure. These external forces thus comprise an organization's task environment (Dill, 1958; Duncan, 1972).

Two dimensions of the task environment are dynamism (the rate of change, variability, or volatility) and complexity (the number of environmental factors impacting the organization and their diversity). Because dynamism explains environmental uncertainty at the decision unit level better than complexity (Duncan, 1972), this study will focus on environmental dynamism.

Dynamism refers to the amount of nonsystematic change (i.e. the rate of unpredictable change) encountered in the firm’s task environment (Bourgeois, 1978). Environmental variability, volatility, or dynamism can “... arise from intense competition, resource scarcity, and fluctuations in demand' (Dwyer and Welsh, 1985, p. 401) as well as from a rapidly changing regulatory climate, turbulence in capital markets, and perturbations in the supply of labor.

\section{Marketing strategies}

An organization's strategy refers to the pattern of major or minor decisions about its domain (Mintzberg, 1978; Miles and Snow, 1978). Business strategy deals with how an organization competes within a particular product/market segment (Hofer and Schendel, 1978). Because an individual strategic business unit (SBU), such as a specific product line (e.g. Holiday Corporation's Hampton Inns) or an individual property within that line (e.g. the Exit 37 Hampton Inn), operates in a particular task environment, the SBU is an appropriate unit of analysis. In this research, we focus specifically on the individual property SBU as the unit of analysis.

Although no generally accepted typologies of business-level strategy exist, Walker and Ruekert (1987), Miles and Snow (1978) and Porter (1980) have attempted to develop such a typology. 
In Porter's (1980) classification scheme, an SBU can choose among three alternative strategies: (1) cost leadership where the SBU strives to maintain a cost advantage over its rivals; (2) differentiation where the SBU attempts to create a product or service that is perceived universally as being unique; and (3) focus where an SBU concentrates on a particular market segment or product/service offering.

The Miles and Snow (1978) typology classifies the different capabilities displayed by SBUs within the same industry (Snow and Hrebiniak, 1980). The typology is based on an SBU's orientation toward product/market development and consists of four strategy types: (1) defender organizations which emphasize production efficiency, applied engineering, and financial control; (2) prospectors which emphasize innovation through product development and effective market knowledge; (3) analyzers which blend aspects of both defenders and prospectors by imitating the successful product innovations of prospectors (to avoid large investment and risk), adapting them to efficient production, and marketing them heavily; and (4) reactor organizations which have no clearly defined competencies, pattern, or focus.

As Walker and Ruekert (1987) note, Porter's (1980) typology is based upon the competitive actions an SBU might take, while the foundation for the Miles and Snow (1978) classification scheme is the intensity of product/market development. Since the latter is better suited to the overall aims of this study, we employ it.

\section{Performance}

The heart of strategic management is improving an organization's performance (Venkatraman and Ramanujam, 1986). Performance may be evaluated on at least three key dimensions: efficiency, effectiveness, and adaptiveness (Ruekert, Walker, and Roering 1985). In this research, we limit our study of hotel performance to two key facets of efficiency. First, revenue per room indicates how efficiently the hotel utilizes an important fixed input, its rooms. Second, net income as a percent of sales, on the other hand, reflects how efficiently the firm converts sales revenues into profits. 


\section{The hypotheses}

The extent to which a particular strategic business unit is vertically controlled depends upon the match between its business strategy and its environment (Harrigan, 1983, p. 40). Hotels are no different. Thus, the first overall hypothesis to be tested is:

HI: The extent to which a hotel is vertically controlled (i.e. its vertical structure) is a function of the interaction between its business strategy and the degree of variability in its task environment.

The specific composition of this interaction is described below.

Defenders emphasize efficiency; therefore, it seems likely that they require tight control over their operations. Such control enables scale economies in buying, production, and promotion and reduces any opportunistic behavior (cf. Harrigan, 1983; Walker and Ruekert, 1987).

Further, more variability in the environment is expected to be associated with lesser degrees of vertical control in the hotel industry. Independents are better able to adapt to changing demand and supply conditions than are the more vertically controlled hotels (cf. Guiltinan, 1974; Harrigan, 1983; Day and Klein, 1987).

Countering this, however, are valid reasons why greater environmental variability might lead hoteliers to more vertically controlled structures.

First, the larger scale of more vertically controlled operations allows hotel managers to devote more, specialized resources (e.g. marketing research) toward understanding environmental forces. By virtue of these resources, more vertically controlled hotels are better able to cope with environmental variability than are less vertically controlled ones (cf. Achrol, Reve, and Stern, 1983).

Another reason for expecting higher levels of environmental variability to be associated with more extensive vertical control is that such control enables a firm to "...restructure dependence so that it becomes more manageable” (Dwyer and Welsh, 1985, p. 401). For instance, an expanding hotelier, under conditions of heavy competition, might set up its own travel agency to feed its customers. An example of this is Radisson Hotels with its Carlson Travel Agencies (Lewis and Chambers, 1989).

A third possibility exists. Often, environmental variability makes it difficult to accurately attribute performance to the individual hotel's efforts or to the environmental conditions 
themselves. When this occurs and when transaction specific assets (i.e. those assets devoted to a particular operating arrangement and cannot be easily transferred to another one) are involved, vertical control is used to overcome the potential for opportunistic behavior.

Although they did not separate these latter two explanations, Dwyer and Welsh (1985) found some empirical support for the notion that higher environmental variability is associated with less complex marketing channel structures (e.g. less vertically controlled ones). In addition, Hambrick (1983, pp. 22-23) found some empirical evidence that defenders were more vertically controlled than were prospectors, apparently because they expected little variability in their task environments.

On balance, this discussion implies that vertically controlled hotels are more likely to follow a defender strategy and to be more prevalent in volatile task environments. Accordingly, the first subhypothesis is:

Hla: Hotels following a defender strategy are likely to be more vertically controlled as their degree of perceived environmental uncertainty increases.

In contrast, prospectors emphasize innovation in their approach to both products and markets. Flexibility is necessary to successfully implement this strategy. Thus, independent hotels are expected to be most closely associated with the prospector strategy, regardless of the degree of variability they perceive in their task environments (cf. Hambrick, 1983; Harrigan, 1983). Hence, the second subhypothesis may.be stated as follows:

Hlb: For hotels following a prospector strategy, their extent of vertical control (i.e. their vertical structure) is not significantly related to their degree of perceived environmental variability.

Hotels following an analyzer business strategy attempt to reap the benefits of both the defender and the prospector strategies. Environmental stability allows these firms to use vertical control to achieve the advantages of scale economies. With higher levels of environmental volatility, however, analyzers are expected to use less vertical control so that they can be more flexible to pursue new products and develop new markets. This discussion is summarized in the third and final subhypothesis:

Hlc: Hotels pursuing an analyzer strategy will be more vertically controlled, the lower the degree of perceived environmental variability they face. 
The end result of an appropriate coalignment among a hotel's particular task environment, its strategy, and its vertical structure should be reflected in greater organizational performance (ef. Ruekert etal., 1985). The overall hypothesis implied by this contingency view is:

H2: The extent of a hotel's efficiency is a function of the interaction among its strategy, its vertical structure, and the degree of variability in its task environment.

At this stage in our understanding of the contingency approach to marketing strategy, structure, and performance, it is extremely difficult to specify exactly the complex threeway interaction implied in Hypothesis 2. Thus, should the hypothesis not be rejected, any empirical decomposition of the interaction term should be considered as exploratory.

\section{Research design}

\section{Sample}

To test these hypotheses, a cross-sectional, field study of hotel managers was undertaken. Specifically, general managers of a sample of 2000 lodging units with 150 rooms or more, randomly selected from a national database maintained by the public accounting firm of Laventhol \& Horwath, were then sent a mail questionnaire designed to tap the constructs described above. After mail and telephone follow-ups, 162 usable questionnaires were obtained. This response rate compares favorably to that obtained by other researchers surveying lodging industry executives (cf. Schaffer, 1986; Laventhol \& Horwath, 1987).

General characteristics of the responding organizations were examined to determine the effects of response bias. Since no one type of lodging establishment appeared to dominate the sample, its degree of generalizability was believed to be quite high (Miller, Kets de Vries, and Toulouse, 1982).

\section{Instrumentation and scaling}

To measure the hotel's vertical structure (VS) (i.e. its extent of vertical control), each general manager was asked to indicate whether or not his property was: (1) independently owned and managed, (2) franchised, (3) chain managed, (4) chain leased and managed, or (5) chain owned and managed. Higher numbers reflected higher degrees of vertical integration.

The questionnaire items used to measure perceived environmental volatility (PEV) were adapted to the lodging industry context from those used by Miles and Snow (1978, p. 200) and 
further refined by Coleman and Gaetan (1985). The latter research team has demonstrated the internal consistency of this scale.

General managers' perceptions of the variability or volatility in the environments facing their hotels were obtained on six-point semantic differentials ranging from stable to volatile. These differentials were based on 20 items descriptive of the components of a hotel's task environment. Sample items included suppliers' prices charged, competitors' rates charged, customers' demand for new facilities/services, labor availability, and government regulations pertaining to room, food, or beverage quality.

The general managers' responses to these 20 items were then summed to obtain the perceived environmental volatility scores. ${ }^{*}$ Note that larger numbers imply more volatility or variability in the hotel's task environment. Coefficient alpha for the scale was computed to be 0.84 which surpasses Nunnally's (1978) suggested guideline. Thus, the perceived environmental volatility measure used here appears to be reliable.

Although no universally accepted operational measures for the strategy construct exist, Snow and Hrebiniak (1980) have developed and empirically tested operationalizations of the Miles and Snow (1978) strategy typology. A number of criticisms have been levelled against the self-typing measure (see McDaniel and Kolari, 1987, pp. 25-26 for a review); however, Snow and Hrebiniak (1980) and Ginn and McDaniel (1987) have provided evidence of the validity of this measure. For this reason, the self-typing operationalization was used in this study.

From four different strategy descriptions, general managers were asked to pick the one which most closely characterized their hotel. Each of these corresponds to one of the four Miles and Snow' (1978) strategy types: defender (ST1), analyzer (ST2), prospector (ST3), and reactor (ST4). These four strategy descriptors appear in Table 1. Because only six reactors appeared in the sample and because reactors are unlikely to survive in this industry, they were dropped from further analysis, leaving an effective sample size of 156.

\footnotetext{
* A more theoretically sound approach would have been to weight each general manager's perceptions of the volatility of each component of the task environment according to how critical that environmental component was to the hotel property's successful performance. Incorporating such weights in a number of other contexts such as work motivation (Campbell and Pritchard, 1976) and marketing channel power (Lusch and Brown, 1982) did not significantly increase explained variance. For this reason, such weights were not included in the measure of perceived environmental volatility.
} 
Both sales and profitability measures of hotel efficiency were included in this study. Because hotels differ in the number of rooms they have and in the rack rates (i.e. published room tariffs) they charge, both performance measures must account for these basic differences.

The first measure of efficiency, the IBFC ratio, measures how efficiently the hotel is able to convert sales into profitability; it is calculated as:

$$
\text { IBFC ratio }=\text { income before fixed charges/total sales. }
$$

In this ratio,

Income before fixed charges ... is income from all operations before deducting rent, property taxes, property insurance, interest, depreciation, income tax, and reserve for replacement, (Laventhol \& Horwath, 1987, p. 68).

An important advantage of IBFC is that it is not contaminated by the variations due to the unique financial structure of the hotel (interest expense) or the nature of the property ownership (owned, leased, etc.).

Another measure of hotel efficiency is sales per available room (SPAR) per day. This ratio indicates how efficiently the hotel is able to utilize its fixed assets and is calculated as follows:

$$
\text { SPAR }=\text { total sales } / \text { (rooms available } \times \text { days hotel was open). }
$$

The raw data used to compute the IBFC and SPAR ratios were gathered in the survey and represented financial performance for 1987.

These two operationalizations of a hotel's efficiency are universally accepted and uniformly used within the lodging industry. In addition, they are highly relevant in relation to the other variables examined in this study. For these reasons, the financial performance measures appear to be valid operationalizations of the efficiency construct.

To test these hypotheses, hierarchical, moderated, dummy-variable regression was used. Because the strategy types were measured as a nominal scale, dummy variables representing each strategy type (less one, of course) were constructed. Moderated regression simply meant that the interactions among independent variables were tested via regression. Finally, the regression was hierarchical in that the interactions and 'main effects' were tested for significance separately. Thus, the data procedure used here is simply the regression approach to analysis of variance (ANOVA). More detail on each of these variants of the general regression model as well as the regression approach to ANOVA appears in Cohen and Cohen (1983). 
Note that each regression equation included the number of rooms in the lodging unit (RMSAVAIL) to control for the possible effects of organizational size. Also note that because significant main effects in regression equations containing corresponding, significant interaction effects were meaningless (Cohen and Cohen, 1983), they were not interpreted.

\section{Results}

Hypothesis 1 and its subhypotheses

The first hypothesis stated that the extent of a hotel's vertical control depends upon the interaction between its strategy and the degree of variability in its task environment. This hypothesis is tested by simply determining whether the change in the amount of variance explained (or, equivalently, the change in R-square) by adding the PEVXST2 and PEVXST3 interaction terms to the PEV, ST2, and ST3 main effects is statistically significant. The change in R-square was 0.034 with an F-ratio of $3.228(d f=2,149)$ and was statistically significant at $P<$ 0.05. Therefore, Hypothesis 1 could not be rejected.

In addition to the interaction set being statistically significant, the two interaction terms (PEVST2 and PEVST3) were also statistically significant at the P s 0.05 (Table 2A). To test Hypotheses la-1c, the effects of these two interaction terms were decomposed. This was done by substituting values for the dummy variables into the regression equation presented in Table 2A (Cohen and Cohen, 1983). The resulting equations are as follows:

$$
\begin{aligned}
& \text { For defenders; VS }=6.604+0.004 \mathrm{RMSAVAIL}+0.033 \mathrm{PEV} \\
& \text { For analyzers: VS }=3.606+0.004 \mathrm{RMSAVAIL}-0.015 \mathrm{PEV} \\
& \text { For prospectors: VS }=4.125+0.004 \mathrm{RMSAVAIL}-0.009 \mathrm{PEV} .
\end{aligned}
$$

As the degree of perceived environmental variability increased for defenders, the extent of vertical control also increased. This result is consistent with Hypothesis 1a. For prospectors, the regression coefficient for PEV indicated a very slight negative relationship between a hotel's degree of vertical control and its perceived environmental variability. This finding appears to be consistent with Hypothesis 1b. Higher levels of vertical control were found for analyzers facing lower degrees of perceived environmental uncertainty. Accordingly, Hypothesis 1c could not be rejected. Overall, then, the findings fail to reject Hypothesis 1 and its subhypothesis. 
Hypothesis 2

That a hotel's efficiency is determined by the interaction of the uncertainty in its task environment, the strategy it pursues, and the extent to which its business activities are vertically controlled is the primary thesis of the second hypothesis. This three-way interaction was tested by examining whether it contributed a statistically significant amount of variance in the two efficiency measures beyond that explained by the PEV, VS, ST2, ST3 main effects and their two-way interactions. Note that the interaction terms are actually sets of interactions necessitated by using dummy variables to represent the strategy types.

For the IBFC measure of hotel efficiency, the change in R-square attributed to the set of three-way interactions amounted to 0.007 which was not statistically significant $(\mathrm{F}=0.604 ; d f=$ 2,146; $P>0.10)$. The R-square change in SPAR due to the three-way interaction set (0.001) was also not statistically significant $(F=0.079$ : $d f=2,146$; $P>0.10)$. Therefore, Hypothesis 2 was rejected.

The next step in the analysis was to explore whether any two-way interactions were significant. The nonsignificant three-way interaction term was pooled into the error term and a main effects with two-way interaction regression model was estimated. For IBFC, the change in F-square due to the set of two-way interactions was 0.028 which was not statistically significant $(\mathrm{F}=2.263 ; d f=2,148 ; P>0.10)$.

Given the size of the F-ratio, further analysis was conducted to determine which, if any, of the two-way interaction terms was contributing to the change in F-square. This analysis indicated that the PEVXST2 interaction term was statistically significant $(P<0.05)$. The relevant equation is reported in Table $2 \mathrm{~B}$.

As before, the Cohen and Cohen (1983) procedure was undertaken to decompose the effects of this significant interaction term. The resulting equations are as follows:

For defenders: IBFC $=0.456-0.0004 R M S A V A I L-0.001 V S-0.0002 P E$

For analyzers: IBFC $=-0.421-0$. Q004RMSAVAIL - 0.001VS + 0.008PEV

For prospectors: IBFC $=0.401-0.0004 R M S A V A I L-0.001$ VS $-0.0002 P E V$.

Except for the intercept term, the equations for defenders and prospectors are identical. Thus, the profitability ratio for hotels pursuing these two strategies declines ever so slightly as the extent of perceived environmental uncertainty increases. Analyzers, however, realize greater profitability with the more uncertainty they perceive. These results, then, indicate that: (1) hotels 
perceiving high degrees of task environment uncertainty can improve their profitability by pursuing an analyzer strategy and (2) hotels following a defender or a prospector strategy may find their profitability declining, albeit slightly, as they perceive higher degrees of task environment uncertainty. Note that the regression coefficient for VS was not statistically significant at the 0.10 level, indicating that vertical structure does not strongly impact a hotel's IBFC ratio.

For SPAR, neither of the two-way interaction terms was statistically significant, nor were any of the main effect terms after the nonsignificant interactions were pooled into the error term. Thus, none of the variables examined here, including the size of the hotel (RMSAVAIL) had any significant impact upon the sales per room measure of hotel efficiency.

\section{Discussion}

Some empirical support was found for the contingency perspective of marketing strategy and structure. In particular, the extent to which a lodging organization is vertically controlled depends upon the match between its strategy and the perceived volatility of its task environment.

Hotels pursuing a defender strategy, for instance, tend toward higher degrees of vertical control with perceptions of increasing environmental variability. As noted earlier, the reasons for this are manifold. Vertical control may enhance defender firms’ abilities to cope with increased environmental volatility; they simply hire the expertise to understand and to develop ways of dealing with unstable task environments. With their emphasis on efficiency, defenders require tight controls over their operations. Vertical control, in the presence of environmental variability, allows defender hotels to guarantee the quality of its service. Finally, because the potential for opportunistic behavior is greater under conditions of environmental volatility, defenders can minimize such behavior through vertical control of various business functions.

The extent of vertical control for prospector hotels and analyzer hotels, on the other hand, declines with increasing perceived environmental volatility. Analyzers appear to be more dramatically affected by this, however. For these firms, the inflexibility inherent in higher degrees of vertical control seems to outweigh their advantages under conditions of greater perceived environmental variability. Thus, prospectors and analyzers opt for the flexibility of more independent operations when they perceive the task environment to be relatively volatile. 
These findings reflect two conflicting arguments typically used to link the degree of vertical control with the extent of task environment variability. One argument is that, when task environments are volatile, firms attempt to gain greater control over their operations (Etgar, 1977; Dwyer and Welsh, 1985). The other argument is that firms rely less on vertical control to enhance their flexibility for adapting to an increasingly volatile environment (Guiltinan, 1974; Harrigan, 1983). The findings reported in this study indicate that both arguments are valid; however, which one obtains depends on the specific strategy pursued by the organization. Thus, these findings underscore the contributions of the contingency perspective of marketing strategy and structure.

Unfortunately, the contributions of contingency perspective to understanding performance in the lodging industry were not quite as dramatic. The three-way interaction among a hotel's strategy, its degree of vertical control, and the dynamism in its task environment was not significantly related to either its profit or sales performance. Indeed, none of the variables studied here were significantly related to the sales per room performance measure. On the other hand, one two-way interaction (i.e. that between perceived environmental uncertainty and the analyzer business strategy) was significantly related to the profit to sales ratio.

The results indicated that analyzers realized higher profitability ratios in volatile environments and lower ones in stable environments. One reason for this might be that, in stable environments, these hotels compete against prospectors and defenders; but, because they do not focus on achieving economies of scale as much as defenders do, their profit margins suffer. In volatile environments, however, these firms are better able to realize lower costs than are prospectors and can reap the rewards of new product innovation and market development. Thus,

analyzers appear to be rewarded by their 'prospector-like' strategies in volatile environments and penalized by their 'defender-like' strategies in stable environments.

In terms of profitability, then, the hybrid analyzer strategy for hotels appears to be superior for conditions of increased task environment variability while either a pure prospector or a pure defender strategy seems superior in stable task environments.

\section{Limitations}

As with any study, this one has a number of features which limit the generalizability of the empirical findings. Future researchers are urged to overcome these limitations. First, the 
sample was composed of larger hotels (i.e. those properties with over 150 rooms); smaller properties should be included in subsequent studies. Second, only two dimensions of a hotel's performance — net profit margin and revenue per room—-were examined. Other dimensions of performance (e.g. effectiveness and adaptability) remain to be investigated. Third, the self-typing measure of business strategy has a number of weaknesses, as outlined by McDaniel and Kolari (1987). Future research is needed to overcome those limitations. Fourth, richer typologies of business strategy, such as the hybrid of the Miles and Snow (1978) and Porter (1980) classification schemes developed by Walker and Ruekert (1987), are needed. And, finally, other facets of environmental uncertainty (e.g. heterogeneity/homogeneity) should be included in future studies. Sixth, richer measures of vertical structure are desperately needed.

\section{Summary and conclusions}

The objective of this study was to examine the contingency perspective of marketing strategy, structure, and performance. Specifically, an organization's vertical structure was posited to depend upon the degree of dynamism in its task environment interacting with the strategy it pursues. In addition, an organization's efficiency was believed to be affected by the match among its vertical structure, its strategy, and the volatility in its task environment.

The context of this study was the lodging industry with the individual hotel property as the unit of analysis.

As the degree of perceived environmental uncertainty increased, hotels pursuing a defender strategy engaged in greater vertical control. Under the same conditions, prospector and analyzer hotels tended to use less vertical control. Thus, the exact relationship between the degree of vertical control and the extent of perceived environmental volatility, at least in the lodging industry, depends upon the strategy the hotel follows.

In terms of performance, no relationship was found between a hotel's sales per room and its strategy, its degree of vertical control, and its perceived task environment dynamism. The profit to sales ratio of hotels following the prospector strategy, however, were found to be positively related to the degree of perceived environmental volatility. 


\section{Acknowledgement}

Support for this study was provided by the Center for Hospitality Research and Service, Virginia Polytechnic Institute and State University, Blacksburg, VA 24061-0429. 
Table 1. The Miles and Snow (1980) strategy typology adapted to the lodging industry

\section{Defender (ST1)}

This type of hotel attempts to maintain a secure niche in a relatively stable customer market segment. The hotel tends to offer a more limited range of services than its competitors, and it tries to protect its position by offering quality at lower prices. Often this type of hotel is not at the forefront of developments in the market-it tends to ignore market changes that have no direct influence on current areas of operation and concentrates instead on doing the best job possible in a limited market segment.

Analyzer (ST2)

This type of hotel attempts to maintain a stable and limited line of services, while at the same time moving out quickly to follow a carefully selected set of the more promising new developments in the market. The hotel is seldom 'first in' with new facilities or services. However, by carefully monitoring the actions of competitors in areas compatible with its stable customer/service base, the hotel can frequently be 'second in' with a more cost- efficient facility or service.

\section{Prospector (ST3)}

This type of hotel typically serves a broad customer/market base that undergoes periodic redefinition. The hotel values being 'first-in' in new facilities/services, even if not all of these efforts prove to be highly profitable. The hotel responds rapidly to early signals concerning areas of opportunity, and these responses often lead to a new round of competitive actions. However, this hotel may not maintain strength in all of the market segments it serves.

\section{Reactor (ST4)}

This hotel does not appear to have a consistent customer/market orientation. The hotel is usually not as aggressive in maintaining established markets and services as some of its competitors, nor is it willing to take as many risks as the competition. Rather, the hotel responds in those areas where it is forced to by pressure from customers, suppliers, competitors, or government regulation. 
Table 2. Moderated, dummy-variable regression results.

A. Determinants of vertical structure (VS)

\begin{tabular}{llll}
\multicolumn{1}{c}{ Variable } & \multicolumn{1}{c}{$\begin{array}{c}\text { Regression } \\
\text { coefficient }\end{array}$} & $\begin{array}{c}\text { Standardized } \\
\text { regression } \\
\text { coefficient }\end{array}$ & t-value \\
RMSAVAIL & .004 & .359 & $4.796 * * *$ \\
PEV & .033 & .372 & $2.116^{* *}$ \\
ST3 & 2.479 & 1.028 & $2.546^{* *}$ \\
ST2 & 2.997 & 1.094 & $2.488^{* *}$ \\
PEVXST3 & -.042 & -1.015 & $-2.346 * *$ \\
PEVXST2 & -.049 & -1.048 & $-2.269 * *$ \\
intercept & 6.604 & & $7.787^{*} *$ \\
R-Square & .207 & & \\
F (6,149) & $6.481 * * *$ & &
\end{tabular}

B. Determinants of net income before fixed charges (IBFC)

\begin{tabular}{llll} 
Variable & \multicolumn{1}{c}{$\begin{array}{c}\text { Regression } \\
\text { coefficient }\end{array}$} & $\begin{array}{c}\text { Standardized } \\
\text { regression } \\
\text { coefficient }\end{array}$ & \multicolumn{1}{c}{$t$-value } \\
\hline RMSAVAIL & $-4.058 E-04$ & -.170 & $-1.971^{*}$ \\
PEV & $-2.019 E-04$ & -.011 & -.122 \\
ST3 & -.055 & -.109 & -1.087 \\
ST2 & -.421 & -.738 & $-1.965^{*}$ \\
VS & -.001 & -.007 & -.078 \\
PEVXST2 & .008 & .800 & $2.124^{* *}$ \\
Intercept & $\mathbf{4 5 6}$ & & $3.356^{* * *}$ \\
F-square & .089 & & \\
F(6149) & $2.425 * *$ & & \\
& & & \\
\hline
\end{tabular}

$* P \leq 0.10, * * P \leq 0.05, * * * P \leq 0.01$. 


\section{References}

Achrol, R. F., Reve, T. and Stern, L. W. (1983) The environment of marketing channel dyads: a framework for comparative analysis. Journal of Marketing 47, 55-67.

Bourgeois, L. J. (1978) Strategy Making, Environment, and Performance: A Conceptual and Empirical Exploration, Unpublished doctoral dissertation, University of Washington, Seattle.

Campbell, J. P. and Pritchard, R. D. (1976) Motivation theory in industrial and organizational psychology, In Handbook of Industrial and Organizational Psychology, M. D. Dunnette (ed.), pp. 63-130. Rand McNally, Chicago.

Coleman, H. and Gaetan, H. (1985) Perceived environmental uncertainty, investment strategy, and reasons for business failure in the apparel industry, Proceedings of the Conference on Apparel Manufacturing, Clemson University, Clemson, SC.

Cohen, J. and Cohen, P. (1983) Applied Multiple Regression/Correlation Analysis for the Behavioral Sciences, Lawrence Erlbaum, Hillsdale, NJ.

Day, G. S. and Klein, S. (1987) Cooperative behavior in vertical markets: the influence of transaction costs and competitive strategies, In Review of Marketing 1987, M. J. Houston (ed.), pp. 39-66. American Marketing Association, Chicago.

Dev, C. S. (1988) Environmental Uncertainty, Business Strategy, and Financial Performance: A Study of the Lodging Industry, Unpublished doctoral dissertation, Virginia Polytechnic Institute and State University.

Dill, W. (1958) Environment as influence on organizational autonomy. Administrative Science Quarterly 2, 409-43.

Duncan, R. B. (1972) Characteristics of organizational environment and perceived environmental uncertainty. Administrative Science Quarterly 17, 313-27.

Dwyer, F. R. and Welsh, M. A. (1985) Environmental relationships of the internal political economy of marketing channels. Journal of Marketing Research 22, 397-414.

Etgar, M. (1977) Channel environment and channel leadership. Journal of Marketing Research 14, 69-76.

Ginn, G. O. and McDaniel, R. R., Jr (1987) Strategic adaptation in the hospital industry, Proceedings, Annual Meeting of the Academy of Management, New Orleans, LA. 
Guiltinan, J. P. (1974) Planned and evolutionary changes in distribution channels. Journal of Retailing 50, 79-91.

Hambrick, D. C. (1983) Some tests of the effectiveness and functional attributes of Miles and Snow's strategic types. Academy of Management Journal 26, 5-26.

Harrigan, K. R. (1983) Strategies for Vertical Integration, Lexington Books, Lexington, MA.

Hofer, C. W. and Schendel. D. (1978) Strategy, Formulation: Analytical Concepts. West Publishing, New York.

Laventhol and Horwath (1987) U.S. Lodging Industry. Philadelphia, PA.

Lenz, R. T. (1980) Environment, strategy, organization structure, and performance: patterns in one industry. Strategic Management Journal 1, 209-226.

Lewis, R. C. and Chambers, R. E. (1989) Marketing Leadership in Hospitality. Van Nostrand Reinhold, New York.

Lusch, R. F. and Brown, J. R. (1982) A modified model of power in the marketing channel. Journal of Marketing Research 19, 312-23.

McDaniel, S. W. and Kolari, J. W. (1987) Marketing strategy implications of the Miles and Snow- strategic typology. Journal of Marketing 51, 19-30.

Miles, R. and Snow, C. (1978) Organizational Strategy, Structure, and Process. McGraw-Hill. New York.

Miller, D., Rets de Vries, M. F. R. and Toulouse, J. M. (1982) Top executive locus of control and its relationship to strategy-making structure, and environment. Academy of Management Journal 25, 237-53.

Mintzberg, H. (1978) Patterns in strategy formation. Management Science 24, 934-48.

Nunnally, J. C. (1978) Psychometric Theory, 2nd edn. McGraw-Hill, New York.

Porter, M. E. (1980), Competitive Strategy. The Free Press, New York.

Ruekert, R. W., Walker, O. C., Jr and Roering, K. J. (1985) The organization of marketing activities: a contingency theory of structure and performance. Journal of Marketing 49. 13-25.

Schaffer, J. D. (1986) Competitive Strategy, Organization Structure, and Performance in the Lodging Industry: An Empirical Assessment of Miles and Snow's (1978) Perspective of Organizations, Unpublished doctoral dissertation, Virginia Polytechnic Institute and State University. 
Snow, C. C. and Hrebiniak, L. G. (1980) Strategy, distinctive competence, and organizational performance. Administrative Science Quarterly 25, 317-36.

Thompson, J. D. (1967) Organizations in Action. McGraw-Hill, New York.

Venkatraman, N. and Ramanujam, V. (1986) Construct measurement in organizational strategy research: a critique and proposal. Academy of Management Review 11, 71-87.

Walker, O. C., Jr and Ruekert, R. W. (1987) Marketing's role in the implementation of business strategies: a critical review and conceptual framework. Journal of Marketing 51, 15-33. 